\title{
Long-term outcomes of concomitant aortic and mitral valve repair
}

\author{
Hunaid A. Vohra, MRCS, MD, FRCS (CTh), FETCS, ${ }^{\text {a }}$ Robert N. Whistance, MRCS, ${ }^{\mathrm{b}}$ Jawad Hechadi, MD, \\ Laurent de Kerchove, MD, ${ }^{\mathrm{a}}$ Hannah Fuller, MBBS, ${ }^{\mathrm{c}}$ Phillipe Noirhomme, MD, ${ }^{\mathrm{a}}$ and Gebrine El Khoury, $\mathrm{MD}^{\mathrm{a}}$
}

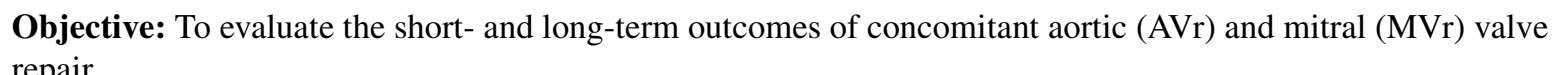
repair.

\begin{abstract}
Methods: This retrospective analysis of prospectively collected data identified patients who had undergone AVr and MVr surgery from March 1996 to October 2009. Patients were included if they had undergone combined repair on the aortic and mitral valves. Excluded were those $<18$ years in whom valve replacement was performed. Data were collected on the short-term morbidity and mortality $(<30$ postoperative days $)$, long-term survival, and freedom from valve-related events and echocardiographic outcomes.

Results: A total of 65 patients underwent $\mathrm{AVr}$ and $\mathrm{MVr}$ (mean age, $56.4 \pm 15.8$ years, 46 men). Preoperatively, 30 patients $(46.1 \%)$ had aortic insufficiency $(\mathrm{AI})>2+, 20$ patients had $\mathrm{AI} \geq 2+$ with aortic dilatation $(30.7 \%)$, and 4 patients $(6.1 \%)$ had aortic dilatation only. Of the 65 patients, 57 had tricuspid $(87.6 \%)$ and 8 had bicuspid aortic valves $(12.3 \%)$. All patients had mitral insufficiency preoperatively. One in-hospital death occurred $(1.5 \%)$. At discharge, no patient had AI $>2+$ versus 30 patients preoperatively $(P<.001)$, and 7 patients had AI $>1+$ versus 61 patients preoperatively $(P<.001)$. At discharge, the mean left ventricular end-diastolic diameter was $48 \pm 7 \mathrm{~mm}$ versus $59 \pm 9 \mathrm{~mm}$ preoperatively $(P<.007)$, and the mean left ventricular end-systolic diameter was $33 \pm 5 \mathrm{~mm}$ versus $38 \pm 14 \mathrm{~mm}$ preoperatively $(P=.36)$. The mean clinical follow-up duration was $62 \pm 45$ months (median, 50; range, 1-177). At the latest follow-up visit, 17 patients were New York Heart Association class $\geq 2$ versus 52 patents preoperatively $(P<.001)$. Four cardiac deaths occurred, and at 1,5 , and 10 years, the freedom from cardiac death was $100 \%, 93.4 \% \pm 3.7 \%$, and $88.5 \%$ $\pm 5.9 \%$, respectively. Eight valve reinterventions were required, and the freedom from valve reintervention at 1,5 , and 10 years was $95.3 \% \pm 2.6 \%, 91.6 \% \pm 3.6 \%$, and $78.4 \% \pm 8.0 \%$, respectively. At 1,5 , and 10 years, the freedom from AI $2+$ was $98.2 \% \pm 1.7 \%, 93.4 \% \pm 3.7 \%$, and $88.3 \% \pm 5.8 \%$ and the freedom from mitral insufficiency $2+$ was $96.4 \% \pm 2.4 \%, 93.3 \% \pm 3.8 \%$, and $93.3 \% \pm 3.8 \%$, respectively.
\end{abstract}

Conclusions: Concomitant $\mathrm{AVr} / \mathrm{MVr}$ is associated with acceptable survival and freedom from valve reintervention. (J Thorac Cardiovasc Surg 2014;148:454-60)

Aortic (AV) and mitral (MV) valve insufficiency coexist in $\leq 10 \%$ of patients undergoing valvular cardiac surgery. ${ }^{1-3}$ Traditionally, concomitant disease has been treated with double valve replacement (DVR), with either mechanical or bioprosthetic valves. Mechanical valves require lifelong anticoagulation and, therefore, have been associated with the risk of major hemorrhage or thrombosis. Bioprosthetic valves do not require anticoagulation but have a limited durability; thus,

From the Department of Cardiovascular and Thoracic Surgery, ${ }^{a}$ Cliniques Universitaires Saint-Luc, Brussels, Belgium; Academic Unit of Surgical Research, ${ }^{\mathrm{b}}$ University of Bristol School of Social and Community Medicine, Bristol, United Kingdom; and University of Birmingham College of Medical and Dental Sciences, ${ }^{\mathrm{c}}$ Birmingham, United Kingdom.

Disclosures: Authors have nothing to disclose with regard to commercial support.

Received for publication June 9, 2013; revisions received Sept 19, 2013; accepted for publication Oct 6, 2013; available ahead of print April 13, 2014.

Address for reprints: Gebrine El Khoury, MD, Service de Chirurgie Cardiovasculaire et Thoracique, Cliniques Universitaires Saint-Luc UCL, Ave Hippocrate 10, Brussels B-1200, Belgium (E-mail: Gebrine.ElKhoury@uclouvain.be). $0022-5223 / \$ 36.00$

Copyright $\Subset 2014$ Published by Elsevier Inc. on behalf of The American Association for Thoracic Surgery

http://dx.doi.org/10.1016/j.jtcvs.2013.10.016 patients can require reoperation during their lifespan. Studies have demonstrated that repairing the MV at the same time as AV replacement (AVR) results in superior outcomes to DVR. ${ }^{4-6}$ Specifically, MV repair (MVr) combined with AVR has been shown to improve overall survival, reduce valve-related complications, and provide advantages for patients who are unable to adhere to intensive anticoagulation regimens. ${ }^{4,6}$

AVR has generally been considered to be the reference standard treatment of AV disease, although, recently, the outcomes of $\mathrm{AV}$ repair (AVr) have improved. ${ }^{7-10}$ The reasons for this have been multifactorial but not least have included a better understanding of the functional anatomy of the $\mathrm{AV}$, the mechanisms underlying aortic insufficiency (AI), and the development of a classification system that informs research and standardizes communication among healthcare professionals. ${ }^{11-13}$ The primary advantage of $\mathrm{AVr}$ is that the native valve will be preserved, which can reduce long-term valve-related complications, ${ }^{7,14}$ prolong survival, ${ }^{15}$ and increase quality of life. ${ }^{16}$ However, the durability of $\mathrm{AVr}$ in the modern era is largely unknown, and reoperation could be required. ${ }^{15}$ Despite the potential 


$$
\begin{array}{ll}
\text { Abbreviations and Acronyms } \\
\begin{array}{ll}
\mathrm{AI} & =\text { aortic insufficiency } \\
\mathrm{AV} & =\text { aortic valve } \\
\mathrm{AVR} & =\text { aortic valve replacement } \\
\mathrm{AVr} & =\text { aortic valve repair } \\
\mathrm{AVr} / \mathrm{MVr} & =\text { combined AV and } \mathrm{MV} \text { repair } \\
\mathrm{DVR} & =\text { double valve replacement } \\
\mathrm{LV} & =\text { left ventricular } \\
\mathrm{MI} & =\text { mitral insufficiency } \\
\mathrm{MV} & =\text { mitral valve } \\
\mathrm{MVr} & =\text { mitral valve repair } \\
\text { NYHA } & =\text { New York Heart Association }
\end{array}
\end{array}
$$

benefits, few studies have evaluated combined $\mathrm{AVr}$ and $\mathrm{MVr}$ (AVr/MVr) for concomitant $\mathrm{AI}$ and mitral insufficiency (MI). ${ }^{17,18}$ The present study, therefore, assessed the long-term outcomes of combined AV and MV reconstructive surgery.

\section{METHODS \\ Study Population}

The present study comprised a retrospective analysis of prospectively collected data from patients undergoing $\mathrm{AVr} / \mathrm{MVr}$ for coexistent $\mathrm{AI}$ and MI. The procedures were performed from March 1996 to October 2006. The indications for surgery included patients with primary severe AI/root dilatation with at least moderate MI, those with severe MI with at least moderate $\mathrm{AI}$ and/or aortic root dilatation, and those with isolated aortic root dilatation with at least moderate MI. Not all valves had organic pathologic features. In 39 patients $(59.9 \%$ ), dilatation of the aortic annulus and/or aorta (type IA, IB, IC, ID) was present without organic aortic valve pathologic features. Thirty patients $(46.1 \%$; type IB, IC, ID) primarily had aortic dilatation. However, owing to the nature of aortic disease, these 4 subtypes are not mutually exclusive and overlap exists among the 4 types. Bicuspid and tricuspid AVs were repaired. Excluded were patients undergoing either MV replacement or AVR and those aged $<18$ years. The local institutional review board waived the requirement for participant consent. All patients routinely underwent echocardiography before surgery to assess the $\mathrm{AV}$ and MV parameters, left ventricular (LV) function, and the LV and proximal aortic dimensions. Coronary angiography was performed preoperatively to identify coexistent coronary disease that might require surgery. Data were collected from the electronic hospital records and bespoke surgical databases. Data extraction included (1) participant demographics (age, gender, height, weight, body surface area); (2) preoperative echocardiographic parameters and New York Heart Association (NYHA) classification; (3) operative characteristics (nature and duration of surgical procedure performed, pathologic findings, concomitant procedures); (4) early postoperative events (mortality, complications, residual AI or MI and AV gradient), and (5) follow-up details (follow-up duration, overall survival, need for valve reintervention, NYHA classification, echocardiographic parameters).

\section{Surgical Technique \\ The techniques of $\mathrm{AVr}^{8,13,14}$ and $\mathrm{MVr}^{19-23}$ have been previously reported.}

\section{Outcomes}

The primary outcome was overall survival, defined as death from any cause from the date of surgery to the latest follow-up visit. The secondary outcomes included in-hospital mortality (defined as death from any cause within 30 days of surgery and/or during the index hospital admission), early complications (within 30 postoperative days), late valve-related events (beyond 30 postoperative days), functional outcomes (NYHA classification), early and late echocardiographic outcomes (AI grade, $\mathrm{AV}$ area, $\mathrm{AV}$ gradient, $\mathrm{MI}$ grade, $\mathrm{LV}$ ejection fraction, $\mathrm{LV}$ dimensions, aortic dimensions), freedom from $\mathrm{AI}>2+$, freedom from $\mathrm{MI}>2+$, and freedom from valve reintervention (any reoperation of the AV or MV, including transcatheter interventions, during follow-up). Valve-related complications were determined by the occurrence of reoperation, bleeding, endocarditis, and thromboembolism, with the help of comprehensive cardiology follow-up clinics, where clinical and echocardiographic parameters were assessed at regular intervals. A composite outcome of freedom from both valve-related mortality and late valve-related events was calculated.

\section{Statistical Analysis}

Statistical analysis was performed using the Statistical Package for Social Sciences, version 16.0 (SPSS, Inc, Chicago, Ill). Data are presented as the mean \pm standard deviation or median and range, as appropriate. To compare the continuous variables, the Student unpaired $t$ test or Mann-Whitney $U$ test was used. For categorical variables, the chi-square or Fisher's exact test were used. The Kaplan-Meier method was used to evaluate time-dependent variables, and comparisons were made between groups using the log-rank test of equality. $P<.05$ was considered statistically significant.

\section{RESULTS \\ Patients}

A total of 65 patients underwent $\mathrm{AVr} / \mathrm{MVr}$ from March 1996 to October 2006 (Table 1). The mean patient age was $57.4 \pm 15.8$ years (median, 59.9; range, 16.4-84.1), and most patients were men $(n=46,70.7 \%)$. Preoperative echocardiography demonstrated that the mean ejection fraction of the included patients was $60 \% \pm 13 \%$, and 12 patients $(18.4 \%)$ had evidence of impaired LV ejection fraction preoperatively $(<50 \%)$. The indications for $\mathrm{AVr}$ were $\mathrm{AI}>2+(\mathrm{n}=30,46.1 \%)$, AI $\geq 2+$ with aortic dilatation $(\mathrm{n}=20,30.7 \%)$, and aortic dilatation only $(\mathrm{n}=4,6.1 \%)$. Six patients $(9.2 \%)$ had previously undergone cardiac surgery (coronary artery bypass grafting in 2, repair of aortic coarctation in 2, ventricular septal defect closure, pulmonary valvotomy, and tricuspid valve repair in 1, and $\mathrm{MVr}$ in 1). The underlying $\mathrm{AV}$ pathologic findings included degeneration $(\mathrm{n}=46 ; 70.7 \%)$, bicuspid AV $(n=8 ; 12.3 \%)$, Marfan's disease $(n=4 ; 6.1 \%)$, rheumatic heart disease $(\mathrm{n}=5 ; 7.7 \%)$, and infective endocarditis $(n=2 ; 3 \%)$. The etiology of MV disease was degenerative $(\mathrm{n}=33 ; 50.7 \%)$, rheumatic $(\mathrm{n}=12$; $18.4 \%)$, endocarditis $(\mathrm{n}=4 ; 6.1 \%)$, functional $(\mathrm{n}=10$, $15.3 \%)$, ischemic $(\mathrm{n}=2,3.0 \%)$, and other findings $(\mathrm{n}=4 ; 6.1 \%)$.

\section{Operative Details}

The operative details are listed in Table 2. The mean cardiopulmonary bypass time was $127.6 \pm 45.4$ minutes, and the mean aortic crossclamp time was $109.9 \pm 50.5$ minutes. The most frequently performed AV procedures 
TABLE 1. Summary of preoperative characteristics $(n=65)$

\begin{tabular}{|c|c|}
\hline Characteristic & Value \\
\hline Age (y) & $56.4 \pm 15.8$ \\
\hline Male gender & $46(70.7)$ \\
\hline \multicolumn{2}{|l|}{ Preoperative echocardiography } \\
\hline Ejection fraction $(\%)$ & $60 \pm 13$ \\
\hline LVEDD $>60 \mathrm{~mm}$ & $26(40.0)$ \\
\hline LVESD $>40 \mathrm{~mm}$ & $20(30.7)$ \\
\hline $\mathrm{AI} \geq 2+$ only & $30(46.1)$ \\
\hline $\mathrm{AI} \geq 2+$ and dilatation & $20(30.7)$ \\
\hline Dilatation only & $4(6.1)$ \\
\hline \multicolumn{2}{|l|}{ Functional AV classification } \\
\hline IA & $9(13.8)$ \\
\hline IB & $15(23.1)$ \\
\hline $\mathrm{IC}$ & $12(18.4)$ \\
\hline ID & $3(4.6)$ \\
\hline II & $23(35.4)$ \\
\hline III & $14(21.5)$ \\
\hline \multicolumn{2}{|l|}{ Etiology of AI } \\
\hline Degenerative & $46(70.7)$ \\
\hline Bicuspid AV & $8(12.3)$ \\
\hline Marfan's disease & $4(6.1)$ \\
\hline Rheumatic heart disease & $5(7.7)$ \\
\hline Infective endocarditis & $2(3.0)$ \\
\hline \multicolumn{2}{|l|}{ Etiology of MI } \\
\hline Degenerative & $33(50.7)$ \\
\hline Rheumatic heart disease & $12(18.4)$ \\
\hline Infective endocarditis & $4(6.1)$ \\
\hline Annular dilatation & $10(15.3)$ \\
\hline Ischemic & $2(3.0)$ \\
\hline Other & $4(6.1)$ \\
\hline
\end{tabular}

Data presented as mean \pm standard deviation or $\mathrm{n}(\%) . L V E D D$, Left ventricular end-diastolic diameter; $L V E S D$, left ventricular end-systolic diameter; $A V$, aortic valve; $A I$, aortic insufficiency; $M I$, mitral insufficiency.

were cusp repair plus annuloplasty $(\mathrm{n}=28,43.1 \%)$, an AV-sparing procedure plus cusp repair $(n=9,13.8 \%)$, an AV-sparing procedure alone $(\mathrm{n}=8,12.3 \%)$, and annuloplasty only $(\mathrm{n}=8,12.3 \%)$. Sixteen David $(24.6 \%)$ and five Yacoub $(7.7 \%)$ procedures were performed. The MV procedures included annuloplasty ring insertion $(\mathrm{n}=52,80.0 \%)$, cusp resection $(\mathrm{n}=18$, $27.7 \%$ ), and neochordae formation $(\mathrm{n}=10,15.4 \%)$. Concomitant procedures were performed in 21 patients $(32.3 \%)$. These included tricuspid valve repair $(n=10)$, coronary artery bypass grafting $(n=7)$, coronary artery bypass grafting plus a Dor procedure $(n=1)$, tricuspid valve repair plus a maze procedure $(n=1)$, maze procedure $(n=1)$, and excision of a left atrial myxoma $(n=1)$.

\section{Early Postoperative Outcomes}

One in-hospital mortality occurred (1.5\%). Early complications ( $<30$ days after surgery) included atrial fibrillation $(\mathrm{n}=31,47.7 \%)$, re-exploration for hemorrhage ( $\mathrm{n}=5,7.7 \%)$, acute renal failure requiring hemofiltration $(\mathrm{n}=2,3.1 \%)$, lower respiratory tract infection $(\mathrm{n}=2$,
$3.1 \%)$, cerebrovascular events $(\mathrm{n}=2,3.1 \%)$, pericardial effusion $(\mathrm{n}=1,1.5 \%)$, and pleural effusion $(\mathrm{n}=1$, $1.5 \%)$. No cases of deep sternal wound infection or early infective endocarditis developed. Two patients required permanent pacemaker insertion (one for complete heart block and the other for symptomatic slow atrial fibrillation). One patient (end-systolic diameter, $46 \mathrm{~mm}$ ) who had undergone $\mathrm{AVr}$ (subcommissural annuloplasty times 3 plus triangular resection of the right coronary cusp) for severe AI plus MVr (bovine pericardial patch to anterior cusp) required early $\mathrm{AV}$ reoperation (biologic valve replacement) 8 days after surgery. At discharge, no patient had $\mathrm{AI}>2+$ versus 30 patients preoperatively $(P<.001)$ and 7 patients had AI $>1+$ versus 61 patients preoperatively $(P>.001)$. The peak AV gradient was $13.6 \pm 12.4 \mathrm{~mm} \mathrm{Hg}$. The mean LV end-diastolic diameter at discharge was $48 \pm 7 \mathrm{~mm}$ versus $59 \pm 9 \mathrm{~mm}$ preoperatively $(P<.007)$, and the mean LV end-systolic diameter was $33 \pm 5 \mathrm{~mm}$ versus $38 \pm 14 \mathrm{~mm}$ preoperatively $(P=.36)$.

\section{Late Postoperative Outcomes}

The mean clinical follow-up was $62 \pm 45$ months (median, 50; range, 1-177). The clinical and echocardiographic follow-up data were $100 \%$ complete. During the study period, 9 late deaths occurred ( $>30$ days after surgery). The cause of late death included cardiac disease in 3 and cerebral tumor, colorectal cancer, multiple myeloma, myelodysplasia, pneumonia, and multiorgan dysfunction in 1 each. Overall survival at 1, 5, and 10 years was $98.5 \% \pm 1.5 \%, 85.9 \% \pm 5.0 \%$, and $67.3 \% \pm 11.1 \%$, respectively (Figure 1, A). Freedom from cardiac death was $100 \%$ at 1 year, $93.4 \% \pm 3.7 \%$ at 5 years, and $88.5 \% \pm 5.9 \%$ at 10 years (Figure $1, B$ ).

Late complications ( $>30$ days after surgery) occurred in 7 patients. Six valve-related events occurred, including reoperation in 4 (3 for aortic insufficiency and 1 for mitral stenosis), AV endocarditis in 1, and thromboembolism, leading to cerebrovascular accident, in 1 during the follow-up period. Freedom from valve-related events was $96.9 \% \pm 2.1 \%, 92.4 \% \pm 2.7 \%$, and $82.8 \% \pm 7.4 \%$ at 1,5 , and 10 years, respectively (Figure 2, $A$ ). In addition, freedom from the composite outcome of valve-related events and valve-related mortality was $96.9 \% \pm 2.1 \%$, $86.0 \% \pm 5.0 \%$, and $77.0 \% \pm 7.6 \%$ at 1,5 , and 10 years, respectively (Figure 2, $B$ ). Freedom from valve reintervention at 1,5 , and 10 years was $95.3 \% \pm 2.6 \%$, $91.6 \% \pm 3.6 \%$, and $78.4 \% \pm 8.0 \%$, respectively (Figure 3, B). Cardiac reoperations were necessary in 10 patients, 1 of which was performed within 30 days of the primary intervention. These procedures included 8 valve-related reoperations and 2 cardiac transplantations. The valve-related reoperations included $4 \mathrm{MV}$ replacements (for mitral stenosis in 2, for mitral regurgitation in 1, and for infective endocarditis in 1), 2 AVRs, and 
TABLE 2. Summary of operative characteristics $(n=65)$

\begin{tabular}{|c|c|}
\hline Characteristic & Value \\
\hline Cardiopulmonary bypass time (min) & $127.6 \pm 45.4$ \\
\hline Crossclamp time ( $\mathrm{min})$ & $109.9 \pm 50.5$ \\
\hline \multicolumn{2}{|l|}{ Bicuspid AV cusp pathologic features } \\
\hline Cusp prolapse & $8(12.3)$ \\
\hline Coronary cusp & $7(10.8)$ \\
\hline Coronary and noncoronary cusp & $1(1.5)$ \\
\hline \multicolumn{2}{|l|}{ Tricuspid AV cusp pathologic features } \\
\hline Cusp prolapse & $21(32.3)$ \\
\hline Noncoronary cusp & $4(6.2)$ \\
\hline Right coronary cusp & $10(15.4)$ \\
\hline Left coronary cusp & $3(4.6)$ \\
\hline Right and left coronary cusps & $1(1.5)$ \\
\hline Noncoronary and right coronary cusps & $3(4.6)$ \\
\hline \multicolumn{2}{|l|}{ Aortic valve procedures $(n=65)$} \\
\hline Cusp repair & $44(67.7)$ \\
\hline Annuloplasty & $42(64.6)$ \\
\hline Valve sparing & $24(36.9)$ \\
\hline Ascending aorta replacement & $15(23.0)$ \\
\hline \multicolumn{2}{|l|}{ Bicuspid aortic valve repair $(n=8)$} \\
\hline Raphe repair & $7(87.5)$ \\
\hline Shaving & $1(12.5)$ \\
\hline Gore-Tex reinforcement & $5(62.5)$ \\
\hline Direct suture & $5(62.5)$ \\
\hline Plication & $2(25.0)$ \\
\hline Subcommissural annuloplasty & $5(62.5)$ \\
\hline \multicolumn{2}{|l|}{ Tricuspid aortic valve repair $(\mathrm{n}=57)$} \\
\hline Plication & $16(28.0)$ \\
\hline Triangular resection & $1(1.7)$ \\
\hline Gore-Tex reinforcement & $6(10.5)$ \\
\hline Subcommissural annuloplasty & $43(75.4)$ \\
\hline Sinotubular junction plication & $8(14.0)$ \\
\hline Shaving and decalcification & $13(22.8)$ \\
\hline Decalcification & $3(5.2)$ \\
\hline \multicolumn{2}{|l|}{ Concomitant procedures } \\
\hline TV repair & $10(15.4)$ \\
\hline $\mathrm{CABG}$ & $7(10.8)$ \\
\hline $\mathrm{CABG}+$ Dor & $1(1.5)$ \\
\hline $\mathrm{TV}$ repair + maze & $1(1.5)$ \\
\hline Maze & $1(1.5)$ \\
\hline Excision left atrial myxoma & $1(1.5)$ \\
\hline \multicolumn{2}{|l|}{ Aortic prosthesis } \\
\hline Straight graft & $15(23.1)$ \\
\hline Valsalva & $9(13.8)$ \\
\hline Aortic prosthesis size $(\mathrm{mm})$ & $28.0 \pm 2.6$ \\
\hline \multicolumn{2}{|l|}{ Mitral valve procedures } \\
\hline Annuloplasty & $52(80.0)$ \\
\hline Cusp resection & $18(27.7)$ \\
\hline Neochordae & $10(15.4)$ \\
\hline Closure of perforation & $2(3.1)$ \\
\hline Commissuroplasty & $6(9.2)$ \\
\hline Annular decalcification & $5(7.7)$ \\
\hline Chordal transfer & $1(1.5)$ \\
\hline Papillary muscle splitting/repositioning & $3(4.6)$ \\
\hline Alfieri & $5(7.7)$ \\
\hline Tricuspid autograft & $3(4.6)$ \\
\hline
\end{tabular}

TABLE 2. Continued

\begin{tabular}{lc}
\hline \multicolumn{1}{c}{ Characteristic } & Value \\
\hline Flip-over & $1(1.5)$ \\
Patch augmentation & $5(7.7)$ \\
Sliding plasty & $6(9.2)$ \\
Annular plication & $4(6.2)$ \\
Other & $2(3.1)$ \\
Ring annuloplasty size $(\mathrm{mm})$ & $31.3 \pm 3.0$ \\
\hline
\end{tabular}

Data presented as mean \pm standard deviation or $\mathrm{n}(\%) . A V$, Aortic valve; $T V$, tricuspid valve; $C A B G$, coronary artery bypass grafting.

1 combined $\mathrm{AVr}, \mathrm{MVr}$, and tricuspid valve repair. Freedom from cardiac reoperation was $95.3 \% \pm 2.6 \%$, $87.5 \% \pm 4.5 \%$, and $74.3 \% \pm 8.2 \%$ at 1,5 , and 10 years, respectively (Figure 3, $A$ ).

The mean echocardiographic follow-up duration was $57 \pm 45$ months (median, 49; range, 1-169). At the final follow-up visit, 4 patients had $\mathrm{AI}>2+$, and the peak aortic gradient was $16.9 \pm 10.7 \mathrm{~mm} \mathrm{Hg}$. No difference was found between $\mathrm{AI} 1+$ at discharge compared with $\mathrm{AI} 1+$ at latest follow-up $(P=.10)$. The mean gradient of the AVs was $5.9 \pm 7.5 \mathrm{~mm} \mathrm{Hg}$ at discharge versus $12.45 \pm 7.48 \mathrm{~mm}$ $\mathrm{Hg}$ at the latest follow-up visit $(P=.2)$. At 1,5 , and 10 years, the freedom from AI $2+$ was $98.2 \% \pm 1.7 \%$, $93.4 \% \pm 3.7 \%$, and $88.3 \% \pm 5.8 \%$, respectively (Figure $4, A$ ). One patient had MI grade $>2+$ at the latest follow-up examination, with freedom from MI $2+$ of $96.4 \% \pm 2.4 \%, 93.3 \% \pm 3.8 \%$, and $93.3 \% \pm 3.8 \%$ at 1,5 , and 10 years, respectively (Figure 4, B). At the latest follow-up visit, 17 of 65 patients were NYHA class $\geq 2+$ postoperatively compared with 52 of 65 patients preoperatively $(P<.001)$.

\section{DISCUSSION}

Surgical interventions that preserve the native heart valves have emerged as attractive alternatives to valve replacement in recent years. The perceived benefits of valve-sparing procedures have been that they negate the need for lifelong anticoagulation (in contrast to mechanical prostheses) and can be associated with fewer valve-related complications, including hemorrhage, thromboembolism, endocarditis, and degeneration. ${ }^{7}$ Concerns have, however, been raised about the durability of the repairs and the need for reoperation and valve replacement at a later date. Although numerous studies have reported the outcomes for single valve repair, especially for the $\mathrm{MV}^{4-6}$ little previous work has considered the effectiveness of dual valve repair. ${ }^{17,18}$ The present study, therefore, examined the outcomes for $\mathrm{AVr} / \mathrm{MVr}$. $\mathrm{AVr} / \mathrm{MVr}$ was shown to be safe in the short term and to have acceptable overall survival and freedom from valve-related events for $\leq 10$ years after the primary surgery. In addition, few patients required valve-related cardiac reoperation during the follow-up period. This suggests that $\mathrm{AVr} / \mathrm{MVr}$ is an 


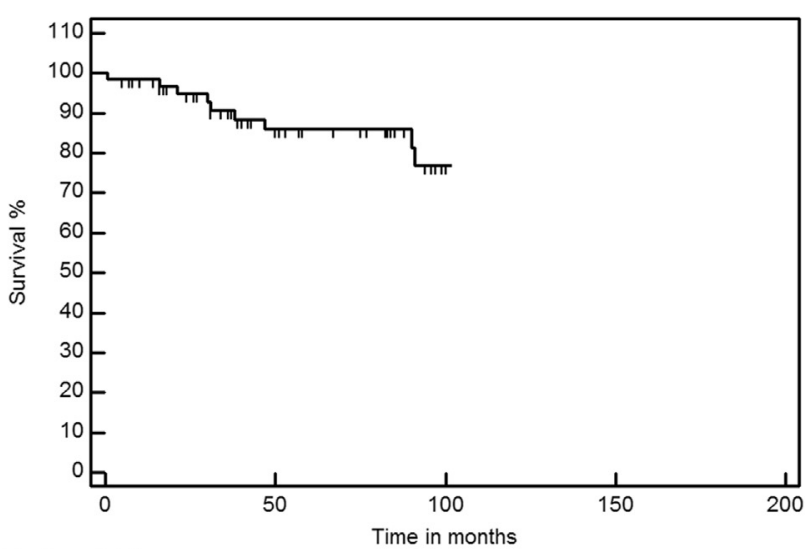

Number at risk 65

A

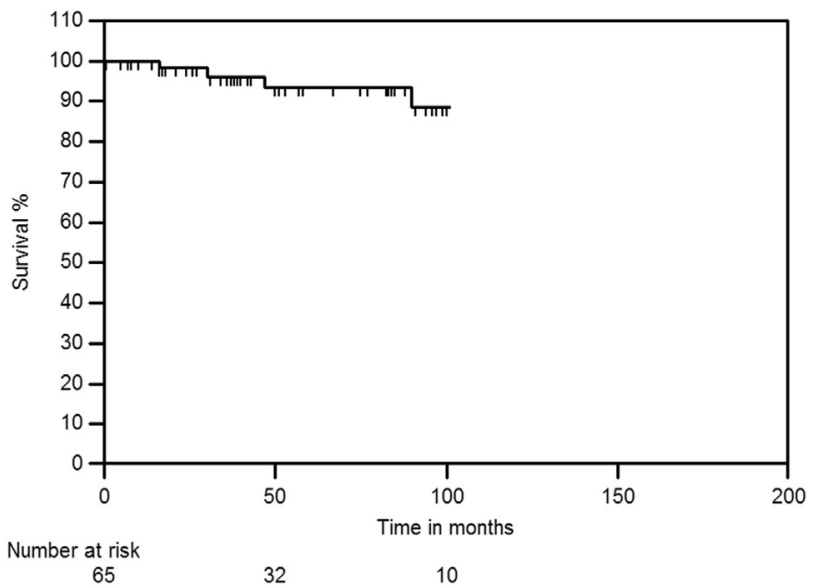

B

FIGURE 1. A, Kaplan-Meier curve showing overall survival (number of patients at risk at different intervals given below the curve). B, Kaplan-Meier curve showing cardiac survival (number of patients at risk at different intervals given below the curve).

effective alternative to DVR or AVR plus MVr in patients with concomitant AI and MI.

Gillinov and colleagues ${ }^{17}$ conducted the largest study to date to investigate the outcomes of $\mathrm{AVr} / \mathrm{MVr}$. In their retrospective case series of 158 patients, they reported low rates of operative mortality ( $3 \%$ ) and overall survival of $93 \%, 82 \%$, and $62 \%$ at 1,5 , and 10 years postoperatively. Late death was shown to be associated with old age, aortic stenosis, and LV dysfunction on multivariate analysis. ${ }^{17}$ In addition, they demonstrated acceptable freedom from reoperation, with a rate of $94 \%, 82 \%$, and $65 \%$ at 1,5 , and 10 years, respectively. The risk factors for reoperation included severe AI, aortic cusp shaving, mitral valve chordal transfer, and bovine pericardial annuloplasty. Most reoperations occurred in patients with rheumatic disease, who included almost $50 \%$ of their cohort. However, rheumatic etiology per se did not emerge as a

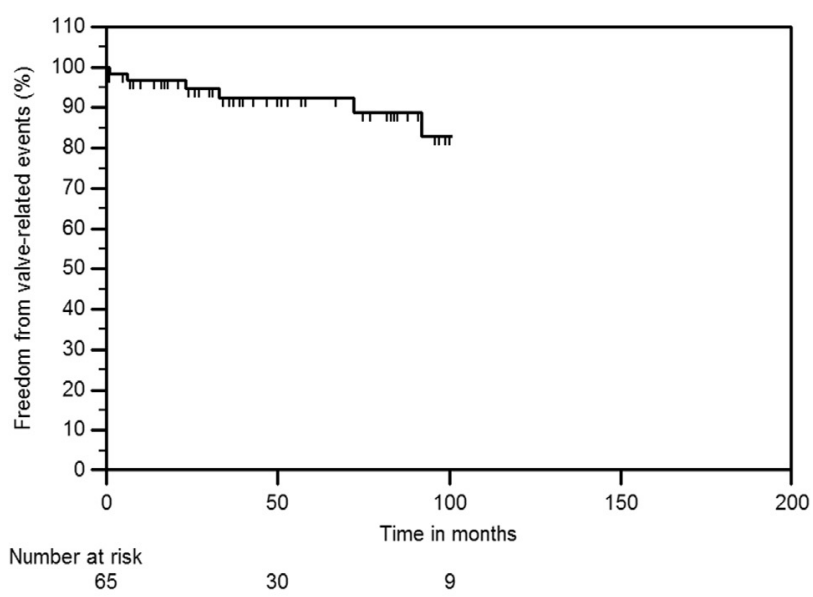

A

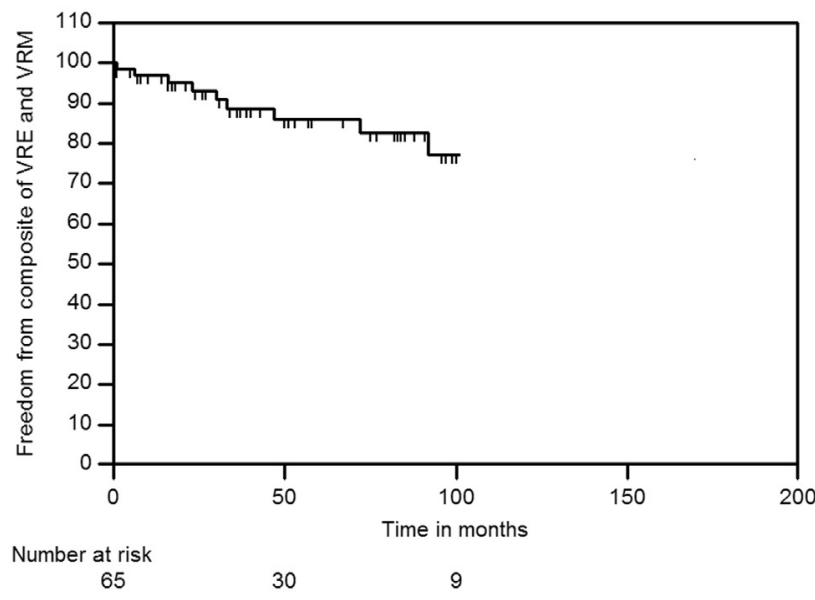

B

FIGURE 2. A, Kaplan-Meier curve showing freedom from valve-related events (number of patients at risk at different intervals given below the curve). B, Kaplan-Meier curve showing freedom from valve related-events $(V R E)$ and valve-related mortality (VRM) (number of patients at risk at different intervals given below the curve).

risk factor for reoperation. ${ }^{17}$ Valve-related complications were also low in this series with freedom from valve-related complications of $99 \%, 95 \%$, and $94 \%$ at 1,5 , and 10 years, respectively. ${ }^{17}$ In the case of severe rheumatic disease, durability was limited for both AVs and MVs. ${ }^{8,17,19,22}$ Despite our aggressive approach to the repair of rheumatic valves, only $8 \%$ and $18 \%$ of our $\mathrm{AVs}$ and MVs, respectively, were rheumatic. The likely reason for this was that we studied surgery for MI; thus, patients who had undergone surgery for mitral stenosis secondary to rheumatic heart disease were excluded. In the triple valve repair series by Grinda and colleagues, ${ }^{24}$ about one half of the patients had rheumatic disease; however, their results were good. Although degenerative MV disease affecting the anterior cusp of the MV has been suggested as a risk factor for reoperation, ${ }^{17}$ we have not found this in our single valve series. ${ }^{21,23}$ In a small series of 


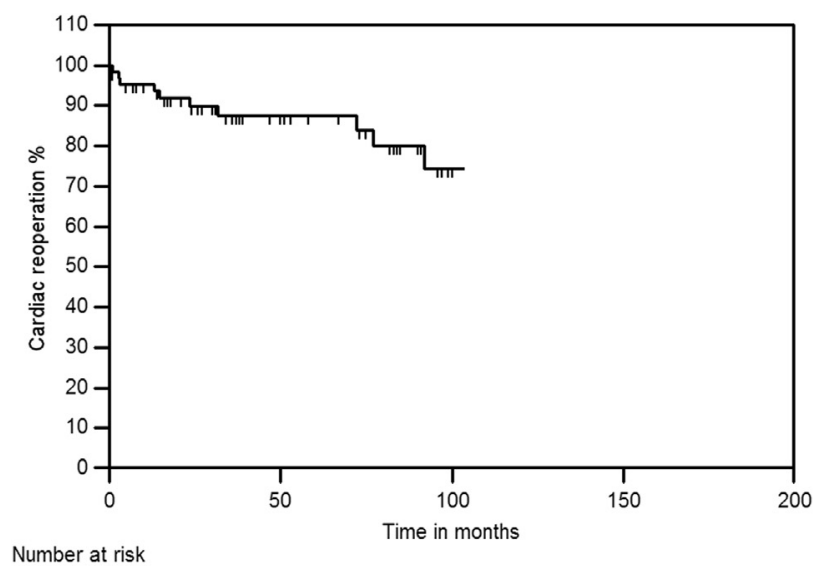

65

29

8

\section{A}

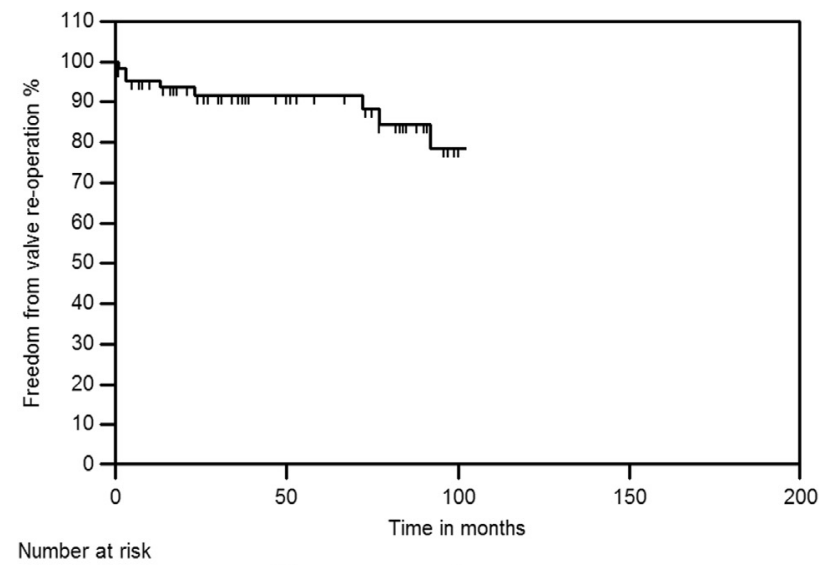

65

31

8

\section{B}

FIGURE 3. A, Kaplan-Meier curve showing freedom from cardiac reoperation (number of patients at risk at different intervals given below the curve). B, Kaplan-Meier curve showing freedom from valve reoperation in all patients (number of patients at risk at different intervals given below the curve).

6 patients by Kazui and colleagues, ${ }^{18}$ no cases of operative mortality or episodes of valve-related complications occurred $\leq 1$ year after surgery. These outcomes are broadly similar to those observed in the present study and highlight that double valve repair is a safe, feasible, and effective alternative to DVR or AVR plus MVr.

Studies have also compared the outcomes for DVR with those for AVR plus MVr. In another study from the Cleveland Clinic, overall survival was significantly better for the patients treated with AVR plus MVr than for those treated with DVR. ${ }^{4}$ In the AVR plus MVr group, overall survival at 5 and 10 years was $79 \%$ and $63 \%$, respectively, and these data are comparable to those in the present study. In addition, freedom from MV reoperation was slightly worse after MVr than after DVR with mechanical prostheses. However, when bioprosthetic valves were used for MVR, freedom from MV reoperation was considerably

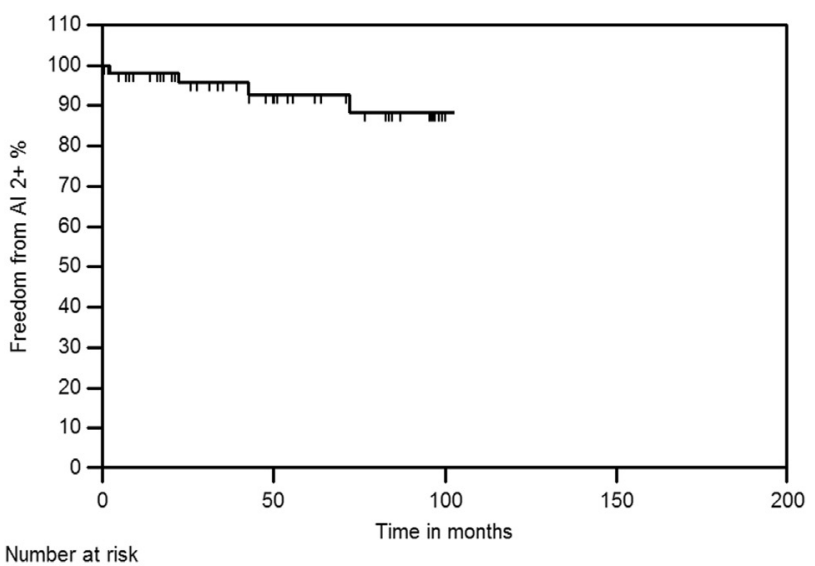

$\begin{array}{ccc}\text { Number at risk } & & \\ 58 & 28 & 8\end{array}$

A

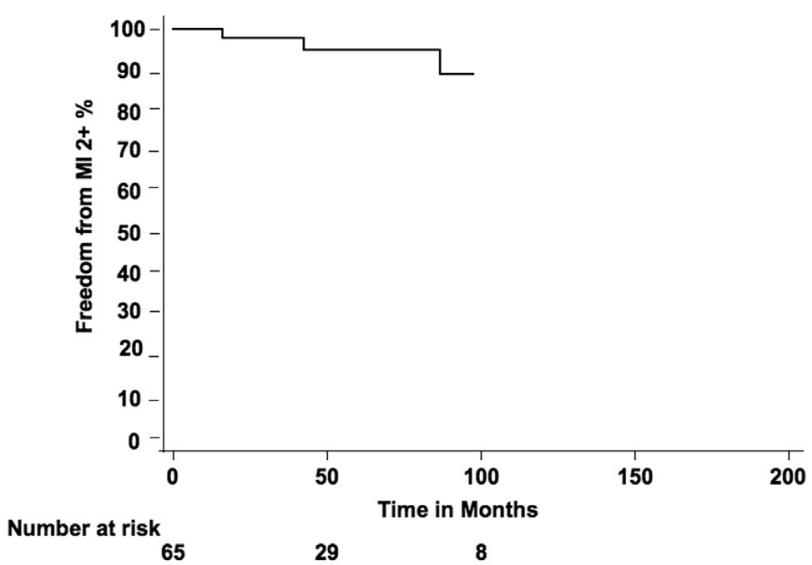

B

FIGURE 4. A, Kaplan-Meier curve showing freedom from aortic insufficiency $(A I) 2+$ (number of patients at risk at different intervals given below the curve). B, Kaplan-Meier curve showing freedom from mitral insufficiency $(M I) 2+$ (number of patients at risk at different intervals given below the curve).

better in the MVr group. In that study, $70 \%$ of both $\mathrm{AVs}$ and MVs were rheumatic, and the study also included stenotic valves. Hence, the study population was different from the population included in our study. Other studies of similar design have shown AVR plus MVr to be associated with less frequent major hemorrhage ${ }^{5}$ and better event-free survival ${ }^{6}$ compared with DVR. These studies highlight that MVr plus AVR is superior to DVR; however, studies are required to make comparisons with $\mathrm{AVr} / \mathrm{MVr}$. It could be hypothesized that $\mathrm{AVr} / \mathrm{MVr}$ would confer additional benefits to MVr plus AVR, because both native valves would be retained, and the incidence of valve-related events might be even lower. A repair strategy seems to confer survival benefit in double-valve disease; however, additional studies are needed to address the issue of durability, such as has been done to a considerable extent in single valve disease, for both the MV, and to a lesser degree, the AV. 
The present study is 1 of the first to evaluate the effectiveness of $\mathrm{AVr} / \mathrm{MVr}$; therefore, it is important to consider some of its limitations. Although the techniques involved in valve repair have evolved significantly since their inception, relatively few centers routinely perform such procedures. A learning curve exists for delivering such interventions, and in many centers without specialist expertise, concomitant $\mathrm{AI}$ and $\mathrm{MI}$ might best be managed with techniques individual surgeons are most adept at performing, whether DVR or AVR plus MVr. Wider training internationally in the nuances of $\mathrm{AVr} / \mathrm{MVr}$ is, therefore, warranted to fully evaluate the potential of this treatment option. Second, although the results of the present study can be contrasted with other studies of DVR or AVR plus $\mathrm{MVr}$, meaningful and valid comparisons can only be undertaken within the context of larger multi-institutional studies. This, however, might entail additional population heterogeneity and disparate treatment recommendations lacking equipoise, causing selection bias and inconsistent outcomes assessments. ${ }^{25}$

\section{CONCLUSIONS}

The present study has demonstrated that $\mathrm{AVr} / \mathrm{MVr}$ has acceptable long-term survival, freedom from valve-related complications, and acceptable durability. It is, therefore, recommended for use in patients with concomitant $\mathrm{AI}$ and MI. Future comparative studies are required to confirm the effectiveness of $\mathrm{AVr} / \mathrm{MVr}$ against procedures involving valve replacement.

\section{References}

1. Hartz RS, Fisher EB, Finkelmeier B, DeBoer A, Sanders JH Jr, Moran JM, Michaelis LL. An eight-year experience with porcine bioprosthetic cardiac valves. J Thorac Cardiovasc Surg. 1986;91:910-7.

2. Kinsley RH, Antunes MJ, Colsen PR. St. Jude Medical valve replacement: an evaluation of valve performance. J Thorac Cardiovasc Surg. 1986;92:349-60.

3. Baudet EM, Puel V, McBride JT, Grimaud JP, Roques F, Clerc F, et al. Long-term results of valve replacement with the St. Jude Medical prosthesis. J Thorac Cardiovasc Surg. 1995;109:858-70.

4. Gillinov AM, Blackstone EH, Cosgrove DM III, White J, Kerr P, Marullo A, et al. Mitral valve repair with aortic valve replacement is superior to double valve replacement. J Thorac Cardiovasc Surg. 2003;125:1372-87.

5. Ho HQ, Nguyen VP, Phan KP, Pham NV. Mitral valve repair with aortic valve replacement in rheumatic heart disease. Asian Cardiovasc Thorac Ann. 2004; 12:341-5.

6. Talwar S, Mathur A, Choudhary SK, Talwar S, Mathur A, Choudhary SK, et al. Aortic valve replacement with mitral valve repair compared with combined aortic and mitral valve replacement. Ann Thorac Surg. 2001;72:20-7.
7. Aicher D, Fries R, Rodionycheva S, Schmidt K, Langer F, Schafers HJ. Aortic valve repair leads to a low incidence of valve-related complications. Eur J Cardiothorac Surg. 2010;37:127-32.

8. Boodhwani M, de Kerchove L, Glineur D, Poncelet A, Rubay J, Astarci P, et al. Repair-oriented classification of aortic insufficiency: impact on surgical techniques and clinical outcomes. J Thorac Cardiovasc Surg. 2009;137: 286-94.

9. Hammermeister K, Sethi GK, Henderson WG, Grover FL, Oprian C, Rahimtoola SH. Outcomes 15 years after valve replacement with a mechanical versus a bioprosthetic valve: final report of the Veterans Affairs randomized trial. J Am Coll Cardiol. 2000;36:1152-8.

10. Oxenham H, Bloomfield P, Wheatley DJ, Lee RJ, Cunningham J, Prescott RJ, et al. Twenty year comparison of a Bjork-Shiley mechanical heart valve with porcine bioprostheses. Heart. 2000;89:715-21.

11. Underwood MJ, El Khoury G, Glineur D, Dion R. The aortic root: structure, function, and surgical reconstruction. Heart. 2000;83:376-80.

12. Fedak PWM, Verma S, David TE, Leask RL, Weisel RD, Butany J. Clinical and pathophysiological implications of a bicuspid aortic valve. Circulation. 2002; 106:900-4.

13. Boodhwani M, El Khoury G. Principles of aortic valve repair. J Thorac Cardiovasc Surg. 2010;140(6 Suppl):S20-2.

14. Boodhwani M, de Kerchove L, Glineur D, Rubay J, Vanoverschelde JL, Noirhomme P, et al. Repair of regurgitant bicuspid aortic valves: a systematic approach. J Thorac Cardiovasc Surg. 2010;140:276-84.

15. Mayer K, Aicher D, Feldner S, Kunihara T, Schafers HJ. Repair versus replacement of the aortic valve in active infective endocarditis. Eur J Cardiothorac Surg. 2012;42:122-7.

16. Aicher D, Holz A, Feldner S, Köllner V, Schäfers HJ. Quality of life after aortic valve surgery: replacement versus reconstruction. J Thorac Cardiovasc Surg. 2011;142:e19-24.

17. Gillinov A, Blackstone E, White J, Howard M, Ahkrass R, Marullo A, et al. Durability of combined aortic and mitral valve repair. Ann Thorac Surg. 2001; 72:20-7.

18. Kazui $T$, Kin $H$, Izumoto $H$, Nakajima $T$, Ishihara $K$, Kawazoe $K$. Combined aortic and mitral valve repair. Asian Cardiovasc Thorac Ann. 2003; 11:319-22.

19. El Oumeiri B, Boodhwani M, Glineur D, De Kerchove L, Poncelet A, Astarci P, et al. Extending the scope of mitral valve repair in rheumatic disease. Ann Thorac Surg. 2009;87:1735-40.

20. de Kerchove L, Vanoverschelde JL, Poncelet A, Glineur D, Rubay J, Zech F, et al. Reconstructive surgery in active mitral valve endocarditis: feasibility, safety and durability. Eur J Cardiothorac Surg. 2007;31:592-9.

21. Chiappini B, Sanchez A, Noirhomme P, Verhelst R, Rubay J, Poncelet A, et al. Replacement of chordae tendineae with polytetrafluoroethylene (PTFE) sutures in mitral valve repair: early and long-term results. J Heart Valve Dis. 2006;15: 657-63.

22. Piciché M, El Khoury G, D’udekem D'akoz Y, Noirhomme P. Surgical repair for degenerative and rheumatic mitral valve disease: operative and mid-term results. J Cardiovasc Surg (Torino). 2002;43:327-35.

23. El Khoury G, Noirhomme P, Verhelst R, Rubay J, Dion R. Surgical repair of the prolapsing anterior leaflet in degenerative mitral valve disease. J Heart Valve Dis. 2000;9:75-80.

24. Grinda JM, Latremouille C, D'Attellis N, Berrebi A, Chauvaud S, Carpentier A, et al. Triple valve repair for young rheumatic patients. Eur J Cardiothorac Surg. 2002;21:447-52.

25. Vohra HA, Whistance RN, de Kerchove L, Punjabi P, El Khoury G. Valve-preserving surgery on the bicuspid aortic valve. Eur J Cardiothorac Surg. 2013;43:888-98. 